\title{
Modelling the deformation of nickel foil during manufacturing of nanostructures on injection moulding tool inserts
}

Sonne, Mads Rostgaard; Cech, Jiri; Pranov, H.; Kofod, G.; Garnæs, J.; Lam, Y. C.; Hattel, Jesper Henri; Taboryski, Rafael J.

Published in:

A I P Conference Proceedings Series

Link to article, DOI:

$10.1063 / 1.4963493$

Publication date:

2016

Document Version

Publisher's PDF, also known as Version of record

Link back to DTU Orbit

Citation (APA):

Sonne, M. R., Cech, J., Pranov, H., Kofod, G., Garnæs, J., Lam, Y. C., Hattel, J. H., \& Taboryski, R. J. (2016). Modelling the deformation of nickel foil during manufacturing of nanostructures on injection moulding tool inserts. A I P Conference Proceedings Series, 1769, [090003]. https://doi.org/10.1063/1.4963493

\section{General rights}

Copyright and moral rights for the publications made accessible in the public portal are retained by the authors and/or other copyright owners and it is a condition of accessing publications that users recognise and abide by the legal requirements associated with these rights.

- Users may download and print one copy of any publication from the public portal for the purpose of private study or research.

- You may not further distribute the material or use it for any profit-making activity or commercial gain

- You may freely distribute the URL identifying the publication in the public portal 


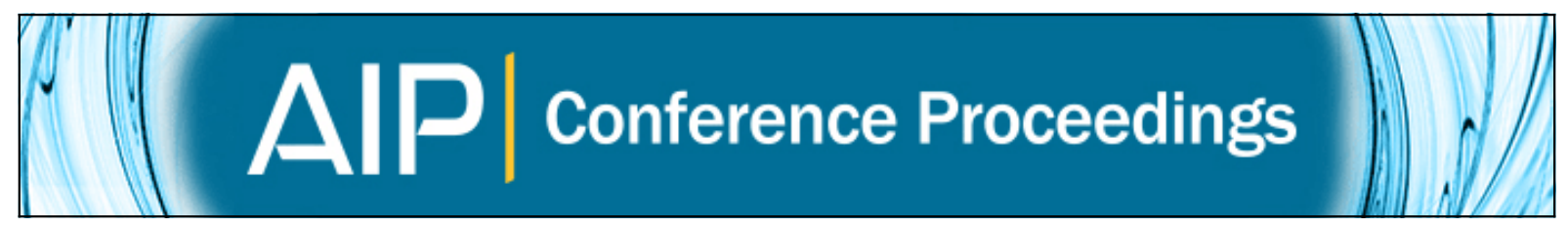

Modelling the deformation of nickel foil during manufacturing of nanostructures on injection moulding tool inserts

M. R. Sonne, J. Cech, H. Pranov, G. Kofod, J. Garnæs, Y. C. Lam, J. H. Hattel, and R. Taboryski

Citation: AIP Conference Proceedings 1769, 090003 (2016); doi: 10.1063/1.4963493

View online: http://dx.doi.org/10.1063/1.4963493

View Table of Contents: http://scitation.aip.org/content/aip/proceeding/aipcp/1769?ver=pdfcov

Published by the AIP Publishing

\section{Articles you may be interested in}

Mould temperature control during injection moulding process

AIP Conf. Proc. 1664, 110012 (2015); 10.1063/1.4918487

Deformation mechanisms during large strain deformation of nanocrystalline nickel

Appl. Phys. Lett. 94, 191902 (2009); 10.1063/1.3132085

Phase transformations during rapid heating of $\mathrm{Al} / \mathrm{Ni}$ multilayer foils

Appl. Phys. Lett. 93, 081903 (2008); 10.1063/1.2975830

Reactive nanostructured foil used as a heat source for joining titanium

J. Appl. Phys. 96, 2336 (2004); 10.1063/1.1769097

Joining of stainless-steel specimens with nanostructured Al/Ni foils

J. Appl. Phys. 95, 248 (2004); 10.1063/1.1629390 


\title{
Modelling the deformation of nickel foil during manufacturing of nanostructures on injection moulding tool inserts
}

\author{
M. R. Sonne ${ }^{1, \text { a) }}$, J. Cech $^{2,3)}$, H. Pranov ${ }^{3)}$, G. Kofod ${ }^{3)}$, J. Garnæs ${ }^{4)}$, Y. C. Lam ${ }^{5)}$, J. H. \\ Hattel $^{1)}$ and R. Taboryski ${ }^{2)}$ \\ ${ }^{1}$ Department of Mechanical Engineering, Technical University of Denmark \\ ${ }^{2}$ Department of Micro - and Nanotechnology, Technical University of Denmark \\ ${ }^{3}$ Inmold Biosystems A/S, Denmark \\ ${ }^{4}$ Danish Fundamental Metrology A/S \\ ${ }^{5}$ School of Mechanical \& Aerospace Engineering, Nanyang Technological University, Singapore \\ a) Corresponding author: mrso@mek.dtu.dk
}

\begin{abstract}
In the present work, a manufacturing process for transferring nanostructures from a glass wafer, to a double-curved insert for injection moulding is demonstrated. A nanostructure consisting of sinusoidal cross-gratings with a period of $426 \mathrm{~nm}$ is successfully transferred to hemispheres on an aluminium substrate with three different radii; $500 \mu \mathrm{m}, 1000 \mu \mathrm{m}$ and $2000 \mu \mathrm{m}$, respectively. The nanoimprint is performed using a $50 \mu \mathrm{m}$ thick nickel foil, manufactured using electroforming. During the imprinting process, the nickel foil is stretched due to the curved surface of the aluminium substrate. Experimentally, it is possible to address this stretch by counting the periods of the cross-gratings via SEM characterization. A model for the deformation of the nickel foil during nanoimprint is developed, utilizing non-linear material and geometrical behaviour. Good agreement between measured and numerically calculated stretch ratios on the surface of the deformed nickel foil is found, and it is shown, that from the model it is also possible to predict the geometrical extend of the nanostructured area on the curved surfaces.
\end{abstract}

\section{INTRODUCTION}

Functional nanostructures on curved surfaces have attracted increasing attention in the industry. Examples of functional nanostructures are well known from nature, where organisms and plants possess optical, adhesive, and self-cleaning capabilities [1]. The scientific literature is rich in examples of advanced materials emulating the wellknown super-hydrophobic effect of the lotus leaf [2] and adhesive surfaces of the gecko's feet [3]. Structural colours and iridescence are most often observed in invertebrates such as butterflies and beetles, but also in the feathers of birds. Parker did in 2000 [4] study the evolution in animal structural colour for 515 million years, and in 2008 Kinoshita et al. [5] studied the physics of such structural colours. Structural colour and iridescence may originate from two fundamentally different structures, 1) interference from multiple layers with different index of refraction, or 2) photonic crystals [6] where light is scattered from regularly spaced nanostructures (e.g. pillars or ridges) on the surface. The aim of the present work is to produce injection moulding tool inserts with the nanostructured functional surfaces as mentioned above. In order to manufacture these structures on the double-curved surfaces of the injection moulding tool inserts, a technology called nanoimprint lithography (NIL) with flexible stamps is an option. In literature, imprinting on simple curved surfaces using flexible materials has recently been demonstrated. Bender et 
al. (2006) [7] investigated the resolution, dimension stability and reproducibility of the Soft UV-Nanoimprint technique. Y-P Chen et al. did in 2008 [8] present their work on fabrication of concave gratings by curved surface UV-nanoimprint lithography, where a pre-shaped film was used to provide a uniform pressure distribution throughout the whole concave substrate. Ji et al. (2010) [9] used UV-SCIL (substrate conformal imprint lithography), with a flexible PDMS stamp in their work on photonic crystals patterning in LED manufacturing. In all these cases, the resolution limit due to distortion of the stamp when applying the pressure, and complications regarding deformations of the flexible stamp, were addressed as major concerns when dealing with flexible stamps on non-planar surfaces. Similar problems also seem to be the main difficulty when doing imprint on curved injection moulding tool inserts. As the nanostructures are created on the flexible stamp in its 2-D planar shape, these structures are bent out of shape when the stamp is plastically deformed during the imprinting process. In order to take this stretching and deformation of the stamp into account, prediction of the nanostructures formed on the nonplanar surface is essential. Here numerical simulation is a vital tool. A manufacturing process very similar to this is sheet metal forming where numerical modelling has been used for decades [10]. Furthermore, methods for experimentally evaluating strains on the surface of sheet metal stampings have been shown in literature [11] where well defined patterns are applied to the surfaces in order to analyse the deformations. In sheet metal forming these patterns are called networks, of which many different types have been presented in literature [12]. Within the field of nanoimprint lithography, there is however a lack of modelling and simulating the deformation process of the flexible stamp on curved surfaces. Recently, Sonne and Hattel [13] presented a model for the constitutive and frictional behaviour of PTFE flexible stamps for nanoimprint lithography, and later its application to nanostructures creating a colour effect [14]. A nickel foil is often used as the imprinting flexible stamp. The reason for that is the way it is manufactured by electroplating, where the nickel is grown on a silicon wafer with the desired nanostructures on its surface. The nanostructures on the nickel foil are then transferred to the curved surface of the actual substrate via embossing into a polymer resist. The aim of this paper is to address the mechanical deformations of the nickel foil during this manufacturing process. A series of experiments is performed, where a nickel foil is used to make nanoimprint of a predefined nanostructure consisting of a sinusoidal cross-grating with a period of $426 \mathrm{~nm}$, on curved aluminium inserts consisting of hemispheres with different radii. A finite element model is developed for simulating the imprinting process, i.e. predicting the distortions and strains acting in the nickel foil during manufacturing. From the deformation of the cross-grating during imprinting, the stretch of the foil is measured and compared with the results obtained from the numerical model.

\section{MANUFACTURING PROCESS}

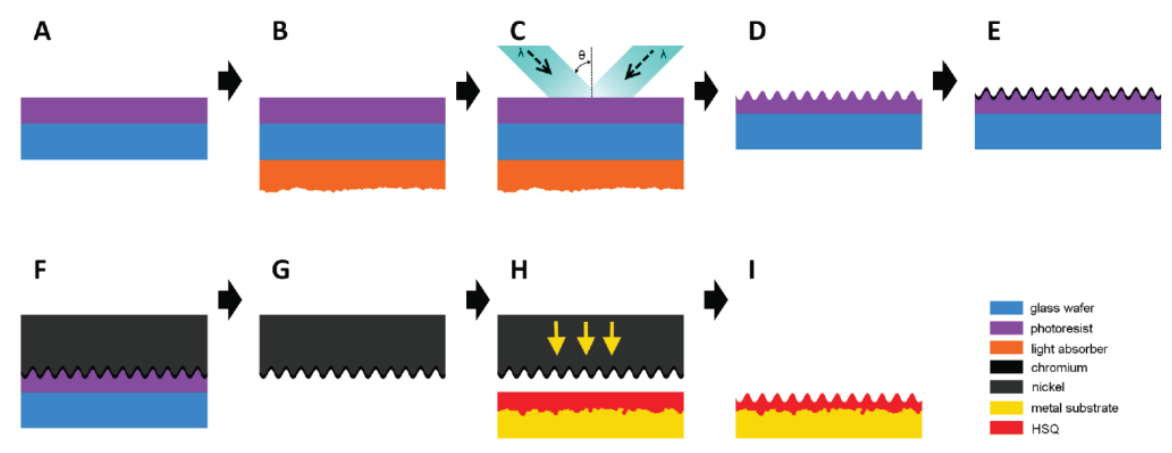

FIGURE 1. Schematic illustration of the manufacturing process, from preparation of the $426 \mathrm{~nm}$ pattern on the wafer (A-D), to electroforming the flexible nickel foil (E-G), further on to nanoimprint lithography into a material called HSQ on top of the final metal substrate $(\mathrm{H}-\mathrm{I})$.

The route from deciding a specific nanostructured surface to having the final tool insert for the injection moulding machine is long and complicated, and includes many different engineering disciplines. In Fig. 1, the manufacturing process used in this work, is schematically shown. First a glass wafer is coated with a thin layer of photoresist (A). On the backside of the glass wafer, an absorber to catch light is deposited (B), and the photoresist is then exposed with two interfering light sources $(\mathrm{C})$, which create a perfectly regular cross-grating with a predefined period. The photoresist is then developed, leaving the desired nanostructure on the glass wafer (D). A thin layer of chromium is then deposited on this surface (E) in order to make it conductive, so that the nickel foil via 
electroplating can be formed (F). The insert tool is planarized with a resist called Hydrogen Silsesquioxane (HSQ), which when cured becomes a hard, durable and tough film, ideal for injection moulds. The nickel foil is then by a huge pressure up to 800 bar pressed into the HSQ $(\mathrm{H})$, making the imprint with the nanostructures. The HSQ on the mould insert is then finally cured, ready to be used for injection moulding of polymer parts (I).

\section{APPLICATION}

The manufacturing process is now applied on three aluminium inserts, which on the surface have a concave part of a hemisphere with varying radius; $500 \mu \mathrm{m}, 1000 \mu \mathrm{m}$ and $2000 \mu \mathrm{m}$, but with a constant height of $200 \mu \mathrm{m}$, see Fig. 2. These inserts are designed with the purpose of investigating, how the nickel foil behaves, when it is applied on curved surfaces with a very small radius of curvature. The deformation of the nickel foil is investigated both experimentally and numerically.

As mentioned, the tested nanostructure is a sinusoidal cross-grating, formed by two exposures using a laser interference method on a $1.5 \mu \mathrm{m}$ thick layer of photoresist, spin-coated on a $100 \mathrm{~mm}$ glass wafer. A polymer backside absorber was used to prevent back reflections of the laser beams into the photoresist. The exposed resists are developed, and the recorded amplitude grating pattern is converted to the surface corrugated phase grating, which is then electroplated with nickel, after coating with the a $60 \mathrm{~nm}$ chromium seed layer. The desired thickness of the electroformed nickel foil depends on the accumulated charge in the electroplating process. For this experiment, films of thickness $55 \pm 4 \mu \mathrm{m}$ are used. The nanostructure period on the nickel foil was measured with an Atomic Force Microscope (AFM) to be $426.2 \pm 0.5 \mathrm{~nm}$. Aluminium alloy 6061 was used as material for the tool inserts. The HSQ resist is then spray-coated on to the aluminium surface with an ultrasonic nozzle. Spray coated films consist of hard, almost solvent-free particles and have to be re-saturated with solvent prior to full cross-linking in order to ensure that the resist will flow during the nanoimprint. The nanoimprint is performed using a special fabricated tool that via a piston with a flat punch face creates a pressure, which presses the nickel foil into the HSQ surface on the aluminium insert tools, see Fig. 2a.
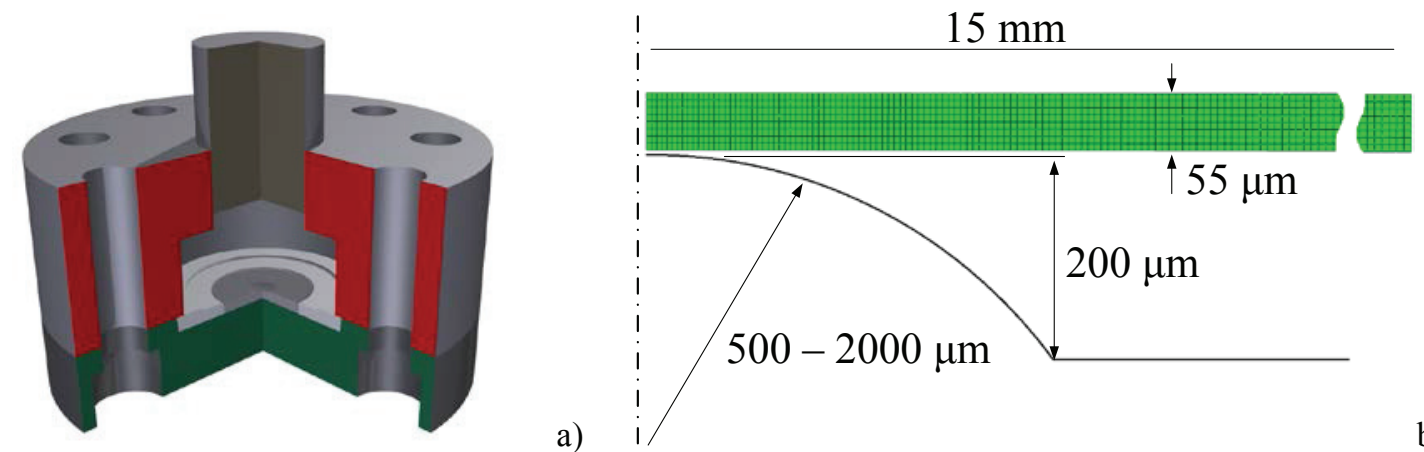

FIGURE 2. a) The device for high pressure nanoimprinting of the nickel foil into the aluminium curved surface, b) Geometry and mesh of the 2-D axisymmetric numerical model

After imprint (60 s at 650 bar) the HSQ film is thermally cured at $400{ }^{\circ} \mathrm{C}$ for 1 hour to ensure that the resist is fully cured, as reported previously in literature [15]. A Scanning Electron Microscope (SEM) (FEI Nova NanoSEM 600 ), operated at low vacuum mode is used to characterize the nanoimprinted surfaces. Using top-view and SEM stage movement, the $X$ and $Y$ periods of the replicated nanostructure are measured on the spherical surfaces, in the alternating positions, while increasing the radial off-center distance. The uncertainty for measuring the $X$ and $Y$ periods is calculated to be $0.64 \%$ for the SEM with adjustable stage. The $X$ and $Y$ periods are then used to calculate the mean period for each of the investigated radial positions.

In order to support the experimentally obtained results a numerical model is developed. To get a better understanding of the mechanical development during the imprinting process, deformation of the nickel foils is 
modelled through numerical simulations via finite element analysis (FEA). Different non-linearities have to be taken into account in order to get proper results; Large deformations make the geometrical calculations non-linear, the material acts elasto-plastic, and finally, contact between substrate and nickel foil adds another non-linearity to the system of equations, which also has to be addressed. The nickel foil is fabricated via electroplating, where the glass wafer in a nickel bath solution works as cathode and by means of a voltage potential nickel is deposited onto the wafer. The mechanical behaviour of the electroplated nickel might be very different from the behaviour of standard metallurgic sheet nickel, as its behaviour is very dependent on the bath and process conditions. The Young's modulus is very dependent on the bath type, and for a sulfamate bath as used in the experiments a value of $E=100$ GPa has been obtained in literature [16]. Hardness measurements of the plated nickel foils were performed and showed to be between $250-300 \mathrm{HV}$, which is within the range of metallurgic nickel sheets [17]. As hardness and yield stress is closely related [18], the electroplated nickel is therefore assumed to have a similar constitutive behaviour as the metallurgical nickel. The system of is numerically discretized through a finite element formulation and solved using the general purpose finite element code ABAQUS (standard). In this case a 2-D axisymmetric model is used, where only aluminum substrate and nickel foil is taken into account, see Fig. 2b. On top of the nickel foil a pressure is applied, which should end up having a value of 650 bar after 60 seconds. However, this cannot instantaneously be applied in the model as this will result in a diverging solution. Instead the pressure needs to be increased gradually, so static equilibrium in subsequent increments has time to adjust.

\section{RESULTS}

From the experiments (deformed nickel is shown in Fig. 3a), it is from SEM and AFM now possible to characterize the embossed $426 \mathrm{~nm}$ sinusoidal cross-grating on the surface of the aluminium tool inserts, see Fig. $3 \mathrm{~b}$. It is seen that the nanostructures are very well replicated onto the metal surface. From the SEM the period of the nanostructures can now be measured, and comparison with the numerical model can be carried out.
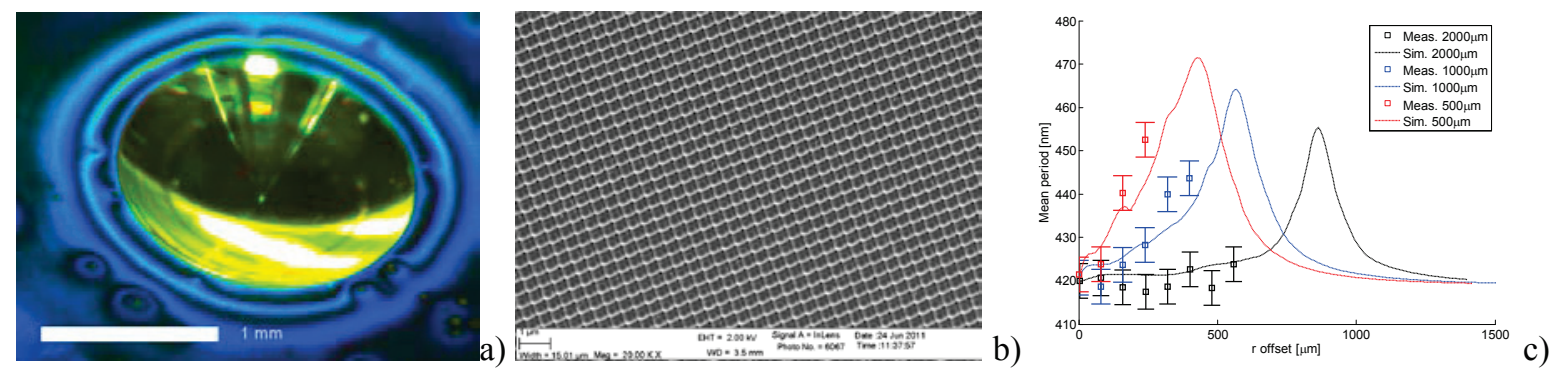

FIGURE 3. a) The deformed nickel after embossing, b) characterization of the nanostructured surface of the aluminum tool inserts with SEM, c) comparison of measured and numerically calculated periods of the nanostructure in the three different test cases.

In order to compare the simulation results with the experiments, the maximum principal logarithmic strain is extracted from the model through a path on the surface on the nickel foil. With a base period of the nanostructure of $426 \mathrm{~nm}$, it is possible to calculate the period on the stretched nickel foil. In Fig. 3c, a comparison between numerical and experimental results of the grid period is shown. It is seen that the results from the simulations well match the measured values of periods from the experiments. The experimental results only show the stretching of the nickel foil, where it was possible to measure the periods of the nanostructures, whereas the results from the FE model further shows the "stretch history" all the way down the spherical cap. From the simulations it is also possible to extract the calculated contact pressure between the nickel foil and the aluminum substrate. 


\section{CONCLUSION}

In the presented work, a manufacturing process for transferring nanostructures from a glass wafer, to a doublecurved insert for injection moulding was demonstrated. A nanostructure consisting of sinusoidal cross-gratings with a period of $426 \mathrm{~nm}$ is successfully transferred to hemispheres on an aluminium substrate with three different radii; $500 \mu \mathrm{m}, 1000 \mu \mathrm{m}$ and $2000 \mu \mathrm{m}$, respectively. The nanoimprint is performed using a $50 \mu \mathrm{m}$ thick nickel foil, manufactured using electroforming. During the imprinting process, the nickel foil is stretched due to the curved surface of the aluminium substrate. Experimentally, it is possible to address this stretch by counting the periods of the cross-gratings via SEM characterization. A model for the deformation of the nickel foil during nanoimprint is developed, utilizing non-linear material and geometrical behaviour. Good agreement between measured and numerically calculated stretch ratios on the surface of the deformed nickel foil is found, and it is shown, that from the model it is also possible to predict the geometrical extend of the nanostructured area on the curved surfaces.

\section{ACKNOWLEDGMENTS}

As a part of the NANOPLAST project, this work is financially supported by The Danish National Advanced Technology Foundation, which is highly acknowledged.

\section{REFERENCES}

1. Pokroy B, Epstein A K, Persson-Gulda M C M, Aizenberg J, Adv. Mater. 2009, 21, 463-469.

2. Barthlott W, Neinhuis C, Planta 1997, 202, 1

3. Ruibal R, Ernst V, Morphol J. 1965, 117, 271.

4. $\quad$ Parker A.R, J. Opt. A 2000, 2, R15-R28.

5. Kinoshita S, Yoshioka S, and Miyazaki J, Rep. Prog. Phys. 2008, 71, 076401.

6. Matejkova-Plskova J, Shiojiri S, Shiojiri M, J. Microsc. 2009, 236, 88-93.

7. M. Bender, U. Plachetka, R. Ji, A. Fuchs, B. Vratzov, H. Kurz, T. Glisner, F. Lindner, J. Vac. Sci. Tech. B 22(6) (2004) 3229-3232.

8. Y-P Chen et al., J. Vac. Sci. Technol. B, 2008, p. 1690.

9. Ji et al., Mic. Eng., 2010, p.963.

10. W. F. Hosford and J. L. Duncan, J. Min. Met. Mater. Soc, 1999, vol. 51, pp. 39-44.

11. R. Sowerby, J. L. Duncan and E. Chu, Int. J. Mech. Sci., 1986, vol. 28, pp. 415-430.

12. R. Pearce, Adam Hilger, Bristol, Philadelphia and New York, 1991.

13. M. R. Sonne, J. H. Hattel , Mic. Eng., 2013, volume 106, pp. 1-8.

14. M.R. Sonne, K. Smistrup, M. Hannibal, J. Thorborg, J. Nørregaard, J.H. Hattel, J. Mat. Proc. Tech., 216 (2015) 418-429.

15. J. Cech, H. Pranov, G. Kofod, M. Matschuk, S. Murthy, R. Taboryski, , Appl. Surf. Sci. 2013(0).

16. J.K. Luo, A.J. Flewitt, S.M. Spearing, N.A. Fleck, W.I. Milne, Mat. Lett. 58 (2004) 2306-2309.

17. The Nickel Development Institute, Ref. Book Series No 11 002, 1988.

18. T. Vedel, Centre of Advanced Electroplating, 1993, DTU (PhD Thesis). 